Article

\title{
Impacts of Composition and Canopy Characteristics of Plant Communities on Microclimate and Airborne Particles in Beijing, China
}

\author{
Shuxin Fan ${ }^{1,2,3}$, Mengyuan Zhang ${ }^{1,2,3}$, Yilun $\mathrm{Li}^{1,2,3}, \mathrm{Kun} \mathrm{Li}^{1,2,3}$ and $\mathrm{Li}$ Dong ${ }^{1,2,3, *}$ \\ 1 School of Landscape Architecture, Beijing Forestry University, Beijing 100083, China; \\ fanshuxin_09@bjfu.edu.cn (S.F.); mengyuanzhang@bjfu.edu.cn (M.Z.); yilunli595@foxmail.com (Y.L.); \\ likun@bjfu.edu.cn (K.L.) \\ 2 Laboratory of Beijing Urban and Rural Ecological Environment, Beijing 100083, China \\ 3 National Engineering Research Center for Floriculture, Beijing 100083, China \\ * Correspondence: dongli@bjfu.edu.cn
}

check for

updates

Citation: Fan, S.; Zhang, M.; Li, Y.;

Li, K.; Dong, L. Impacts of

Composition and Canopy

Characteristics of Plant Communities

on Microclimate and Airborne

Particles in Beijing, China.

Sustainability 2021, 13, 4791.

https://doi.org/10.3390/su13094791

Academic Editor: Carmelo

M. Musarella

Received: 17 March 2021

Accepted: 14 April 2021

Published: 24 April 2021

Publisher's Note: MDPI stays neutral with regard to jurisdictional claims in published maps and institutional affiliations.

Copyright: (c) 2021 by the authors. Licensee MDPI, Basel, Switzerland. This article is an open access article distributed under the terms and conditions of the Creative Commons Attribution (CC BY) license (https:/ / creativecommons.org/licenses/by/ $4.0 /)$.

\begin{abstract}
As the basic component of urban green-spaces, plant communities regulate both the microclimate and air particle levels. Understanding the regulatory mechanism of plant communities represents the theoretical basis for using green spaces to improve the urban climate and mitigate air particle pollution. Based on field investigations, differences in the daily air temperatures (AT), relative humidity $(\mathrm{RH})$, and $\mathrm{PM}_{10}$ and $\mathrm{PM}_{2.5}$ concentrations in eight compositional types of plant communities were quantitatively analyzed. In addition, the correlations between these variables and various canopy parameters were further established in order to detect critical thresholds. The results showed that, among the eight compositional types, significant differences existed in daily AT, $\mathrm{RH}, \mathrm{PM}_{10}$ and $\mathrm{PM}_{2.5}$ levels. The mixed tree, shrub and grass (M-TSG) community had the strongest cooling and $\mathrm{PM}_{10}$ reduction effects; the broad-leafed tree, shrub and grass (B-TSG) community had the best humidifying effect; while the mixed tree and grass (M-TG) community most effectively reduced $\mathrm{PM}_{2.5}$ concentrations. The daily $\mathrm{AT}$ and $\mathrm{PM}_{10}$ concentrations were significantly negatively correlated with canopy density (CD) and leaf area index (LAI), but positively correlated with canopy porosity $(\mathrm{CP})$ and sky view factor (SVF), while these correlations were opposite for daily $\mathrm{RH}$. The response of daily $\mathrm{PM}_{2.5}$ concentrations to canopy characteristics was complex, featuring multiple nonlinear relations. Critical thresholds were found in some cases. Overall, M-TSG or M-TG communities with about $75 \% \mathrm{CD}, 55 \% \mathrm{CP}, 2.5 \mathrm{LAI}$ and $0.18 \mathrm{SVF}$ perform most noticeable both microclimate and air particle regulation services.
\end{abstract}

Keywords: urban green-space; community composition; canopy structure; microclimate; airborne particles

\section{Introduction}

Due to rapid urbanization and industrialization, increased human activity has discharged large amounts of anthropogenic heat and pollutants into the atmosphere, which has triggered a series of urban environmental crises [1]. A large number of studies have reported that land surface temperatures, air temperatures (AT) and air pollutant levels within cities are significantly higher than those in surrounding rural areas [2,3]. The urban heat island (UHI) effect and air pollution have become prominent restrictions to the development of multiple cities in recent years. Taking Beijing as an example, the AT of Beijing has increased significantly at a rate of $0.45{ }^{\circ} \mathrm{C}$ per decade from 1960 to 2018. This has resulted in warmer winters and summer heat anomalies. In 2019, it was recorded that the air quality of Beijing was below the national standard for as much as 125 days, accounting for $34 \%$ of the whole year. Airborne particles remain the main form of air pollutant in Beijing [4]. Continuous high temperatures in urban areas reduce their atmospheric pressure 
to levels lower than the surrounding rural areas. This is not conducive to the diffusion or dispersion of pollutants, creating a reflux back into the urban area [5-7]. High temperatures can also catalyze the secondary reactions of some pollutants, further aggravating the deterioration of urban air quality. The long-term suspension of air particles can form a cover over the city, which not only hinders the outward radiation of urban heat [8], but also absorbs and scatters solar radiation, thus, indirectly contributing to a deteriorating local thermal environment. Therefore, it is crucial to explore the long-term feasibility, economic and effective control strategies for reducing both the UHI phenomenon and air particle pollution from the perspective of sustainable development.

Previously UHI research has mainly focused on the origin, strength, spatial and temporal distribution, simulation and prediction of UHI [9-11], while pollution studies have focused on the component characteristics, source apportionment, attenuation mechanisms and hazard assessment of airborne particles [12-14]. These studies have covered various topics ranging from large-scale analyses based on remote sensing retrieval, to local and micro-scale projects based on field observations and numerical simulations [15-18]. In recent years, the effects of landscape elements on UHI and airborne particle pollution have begun to attract increasing attention. As the most important natural component of the urban ecosystem, green-space is the main provider of urban ecosystem services (ES). Among the many ESs, thermal and particulate matter (PM) regulation services are considered as the key services provided by green-space vegetation. Such services are of great significance in coping with global climate change, alleviating urban heat island effects and improving urban air quality [19-22]. These regulatory services generated from plants can influence the level and distribution of water, heat and PM in the air via transpiration, isolation and blocking, as well as absorption and detention effects [23-25]. However, plants in urban green spaces rarely exist as individuals, but rather as plant communities, which generally refers to vegetation assemblages or patches constructed via plant selection, configuration, planting and management in urban green-spaces. The dense canopy of plant communities, comprising branches and leaves, can absorb and reflect a large amount of solar radiation and exerts a shading effect. Meanwhile, plants' evapotranspiration processes bring water into the air, which transforms and consumes ambient heat, thus, adjusting both the AT and relative humidity $(\mathrm{RH})$ under the tree canopy and its surrounding environment [26-28]. In addition, complex community canopies can change the velocity and direction of airflow, create local circulation and promote the deposition of air particles. Moreover, this is coupled with the detention and absorption of different-sized particles by the canopy branches and leaves, leading to the regulation of airborne particle levels $[29,30]$. Therefore, the basic component of urban green spaces is plant communities. Additionally, when appropriately implemented, plant communities, as a basic functional unit, can produce a regulating effect on both UHI and air pollution.

Plant communities feature multiple composition types. Most scholars believe that different community types have variable effects on cooling, humidifying and are associated with different-sized particle concentrations. The regulatory effects of multi-layer communities dominated by trees are significantly better than those of other types [31,32]. Recently, canopy characteristic effects, such as canopy density (CD), leaf area index (LAI), plant height and ventilation coefficients, on the levels of AT, RH and PM concentrations under the canopy have been reported $[30,33]$. To influence ambient microclimate, $\mathrm{CD}$ and LAI are considered the most important factors affecting AT [34,35]. To influence airborne particle levels, most studies advocate that plant communities with high planting density, $\mathrm{CD}$ and LAI have greater total dust retention capacities, making them more effective at reducing PM [36,37]. However, in some cases, dense vegetation has been found to inhibit air exchange near the ground, which is not conducive to the diffusion and attenuation of PM [38]. Recently, further development of quantitative methods has led some researchers to focus on whether there is a critical threshold for the effects of plant community canopy on microclimate and air particle levels [21,39]. However, there are insufficient results to 
define key thresholds to guide the construction of plant communities in urban areas to regulate these attributes.

Moreover, many studies have shown that there is a complex interaction between AT, $\mathrm{RH}$ and air particles, especially in the case of fine particles [40,41]. Studies have reported fine particles are particularly sensitive to microclimate factors. Some specific AT and RH conditions may not be conducive to the regulation of air particle levels [42]. As previous studies on the regulatory effects of green spaces mostly focused on the mitigation of either UHI or air pollution, they lack comprehensive consideration of both environmental issues $[37,38,43,44]$, which may easily lead to neglecting one or the other in application. Therefore, finding a strategy to balance both issues is highly relevant to the construction of plant communities to improve urban thermal and dust environments.

To quantitatively investigate the regulating mechanisms and influential factors of plant communities on microclimate and air particle levels in highly heterogeneous urban environments, and provide theoretical guidance for future urban green-space design and management optimization, in this paper we focused on characterizing: (1) variations of microclimate and air particle levels in various plant community types; and (2) determining critical thresholds of plant community canopy characteristics on microclimate and airborne particle levels.

\section{Materials and Methods}

\subsection{Study Area and Measurement Sites}

Beijing ( $\left.39^{\circ} 56^{\prime} \mathrm{N}, 116^{\circ} 20^{\prime} \mathrm{E}\right)$, situated in the northern part of the North China Plain, has a monsoon-influenced humid continental climate, with hot and humid summers and generally cold and dry winters. Based on meteorological data for 2019, the annual average temperature of Beijing was $12.5^{\circ} \mathrm{C}$ and the average annual precipitation was $511.1 \mathrm{~mm}$, which mostly occurred in summer. The predominant wind direction in summer was southeast to northeast, while the reverse direction dominated in winter [45]. In 2019, the average concentrations of $\mathrm{PM}_{2.5}$ and $\mathrm{PM}_{10}$ were $42 \mu \mathrm{g} / \mathrm{m}^{3}$ and $60 \mu \mathrm{g} / \mathrm{m}^{3}$ in Beijing [4].

Urban residential areas, featuring highly heterogeneous internal environments and complex underlying surface patterns, which could be considered as "miniatures" of urban environments, are highly suitable for local and micro-scale studies. In this study, Wangjinghuayuan (WJHY; $40^{\circ} 0^{\prime} \mathrm{N}, 116^{\circ} 28^{\prime} \mathrm{E}$ ), Xiuyuan (XY; $\left.39^{\circ} 59^{\prime} \mathrm{N}, 116^{\circ} 24^{\prime} \mathrm{E}\right)$, Shuiduizi $\left(\mathrm{SDZ} ; 39^{\circ} 55^{\prime} \mathrm{N}, 116^{\circ} 28^{\prime} \mathrm{E}\right.$ ) and Hepingjiayuan (HPJY; $39^{\circ} 57^{\prime} \mathrm{N}, 116^{\circ} 25^{\prime} \mathrm{E}$ ) residential areas were selected for field monitoring (Figure 1). These four residential areas are evenly distributed in the northwest Chaoyang District of Beijing, with an average separation distance of $6.58 \mathrm{~km}$ and no large green spaces around them. Their surrounding streets enclose them as internally isolated spaces with typically flat interior terrain. The vegetation coverage in all residential areas is around $40 \%-60 \%$. Descriptions of these four residential areas are given in Table 1.

Table 1. Information about the four sampled residential areas.

\begin{tabular}{|c|c|c|c|c|}
\hline $\begin{array}{c}\text { Residential } \\
\text { Area }\end{array}$ & Build Time & $\begin{array}{l}\text { Total Area } \\
\qquad\left(\mathrm{m}^{2}\right)\end{array}$ & $\begin{array}{l}\text { Vegetation Area } \\
\qquad\left(\mathrm{m}^{2}\right)\end{array}$ & $\begin{array}{c}\text { Vegetation } \\
\text { Coverage } \\
(\%)\end{array}$ \\
\hline WJHY & 2002 & $239,167.20$ & $113,197.80$ & 47.33 \\
\hline$X Y$ & 2003 & $135,437.57$ & $58,915.34$ & 43.50 \\
\hline SDZ & 1993 & $129,022.85$ & $64,214.67$ & 49.77 \\
\hline HPJY & 1985 & $499,524.66$ & $292,521.60$ & 58.56 \\
\hline
\end{tabular}



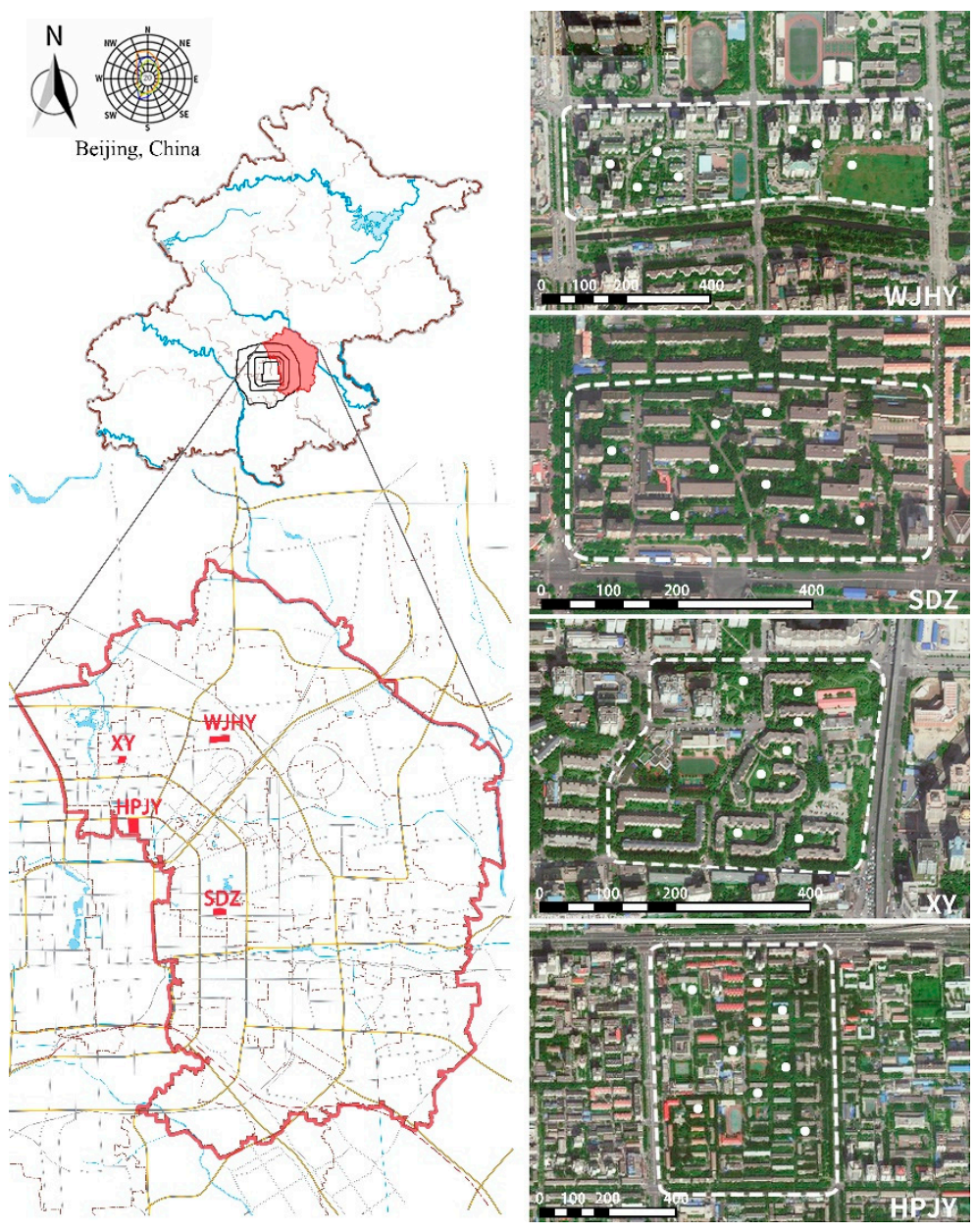

Figure 1. Locations of 4 sampled residential areas and 33 plant community sites (picture source: Google Maps, September 2016).

Experiments aiming at examining the influence of community composition (Experiment A) were carried out in the green spaces of WJHY, XY and SDZ residential areas. Based on pre-investigation, eight plant community types were defined, which are: mixed coniferous and broad-leaved trees, shrubs and grasses (M-TSG); broad-leaved trees, shrubs and grasses (B-TSG); coniferous trees, shrubs and grasses (C-TSG); mixed coniferous and broad-leaved trees and grasses (M-TG); broad-leaved trees and grasses (B-TG); coniferous trees and grasses (C-TG); broad-leaved shrubs and grasses (B-SG); and coniferous shrubs and grasses (C-SG). We selected 24 plant community plots with a size of $10 \mathrm{~m} \times 10 \mathrm{~m}$. Additionally, all these community types are common in Beijing urban green spaces.

Experiments aiming at examining the influence of canopy characteristics (Experiment B) were carried out in the green space of HPJY. We selected nine mixed plant communities with different canopy structures with a size of $15 \mathrm{~m} \times 15 \mathrm{~m}$. Each plot features moderate and similar proportions of trees, shrubs and grasses. We ensured that the distance between the center of each selected community and the surrounding buildings was more than $10 \mathrm{~m}$ to avoid any interference with the measurement results.

Basic information about the above 24 and 9 plots is detailed in Tables 2 and 3, respectively. The locations of the residential areas and 33 plant community plots are shown in Figure 1. 
Table 2. Details of the sampling community for community composition experiment.

\begin{tabular}{ccccc}
\hline No. & $\begin{array}{c}\text { Composition } \\
\text { Types }\end{array}$ & $\begin{array}{c}\text { Average Height } \\
(\mathbf{m})\end{array}$ & $\begin{array}{c}\text { Average Crown } \\
\text { Diameter }(\mathbf{m})\end{array}$ & $\begin{array}{c}\text { Average } \\
\text { DBH/GD (cm) }\end{array}$ \\
\hline A1 & M-TSG & 6.21 & 4.30 & 11.25 \\
A2 & B-TSG & 5.40 & 3.95 & 16.00 \\
A3 & C-TSG & 8.84 & 3.26 & 10.18 \\
A4 & M-TG & 9.29 & 4.46 & 14.53 \\
A5 & B-TG & 2.93 & 2.22 & 15.35 \\
A6 & C-TG & 4.79 & 3.91 & 8.73 \\
A7 & B-SG & 1.63 & 2.48 & 13.44 \\
A8 & C-SG & 0.73 & 1.47 & 5.02 \\
B1 & M-TSG & 4.06 & 3.92 & 18.70 \\
B2 & B-TSG & 3.86 & 5.77 & 8.78 \\
B3 & C-TSG & 7.19 & 3.45 & 8.75 \\
B4 & M-TG & 5.32 & 3.03 & 17.69 \\
B5 & B-TG & 7.39 & 3.30 & 8.13 \\
B6 & C-TG & 5.43 & 2.84 & 12.11 \\
B7 & B-SG & 1.58 & 1.15 & 16.81 \\
B8 & C-SG & 0.58 & 2.08 & 5.25 \\
C1 & M-TSG & 5.32 & 3.19 & 12.87 \\
C2 & B-TSG & 7.91 & 4.54 & 14.36 \\
C3 & C-TSG & 6.27 & 2.63 & 19.67 \\
C4 & M-TG & 8.33 & 4.22 & 20.04 \\
C5 & B-TG & 4.45 & 3.53 & 15.93 \\
C6 & C-TG & 5.32 & 3.08 & 14.04 \\
C7 & B-SG & 1.93 & 2.46 & 7.60 \\
C8 & C-SG & 0.61 & 1.35 & 4.37 \\
\hline
\end{tabular}

Note: $\mathrm{Ax}, \mathrm{Bx}$ and $\mathrm{Cx}$ used to distinguish the plant communities from WJHY, XY, SDZ, respectively. Average height, crown diameter and DBH/GD only for trees and shrubs.

Table 3. Details of the sampling community for community canopy experiment.

\begin{tabular}{ccccc}
\hline No. & $\begin{array}{c}\text { Composition } \\
\text { Types }\end{array}$ & $\begin{array}{c}\text { Average Height } \\
(\mathbf{m})\end{array}$ & $\begin{array}{c}\text { Average Crown } \\
\text { Diameter }(\mathbf{m})\end{array}$ & $\begin{array}{c}\text { Average } \\
\text { DBH/GD(cm) }\end{array}$ \\
\hline D1 & M-TSG & 9.10 & 4.50 & 19.50 \\
D2 & B-TSG & 5.63 & 4.53 & 11.47 \\
D3 & B-TSG & 4.67 & 4.01 & 9.13 \\
D4 & M-TSG & 11.15 & 6.34 & 18.53 \\
D5 & M-TSG & 8.92 & 6.48 & 19.49 \\
D6 & M-TSG & 6.40 & 4.77 & 14.39 \\
D7 & B-TSG & 11.74 & 4.70 & 29.89 \\
D8 & M-TSG & 8.57 & 5.69 & 28.74 \\
D9 & M-TSG & 6.97 & 3.21 & 15.55 \\
\hline
\end{tabular}

Note: Dx refers to the plant communities from HPJY. Average height, crown diameter and DBH/GD only for trees and shrubs.

\subsection{Microclimate and Airborne Particle Level Measurements}

In this study, all monitoring was conducted on clear (pollution levels of mild or good) and windless (wind velocity $<2 \mathrm{~m} / \mathrm{s}$ ) days in summer (July-August 2016) with similar basic weather conditions (AT, RH and air quality) to avoid the influence of significantly different meteorological factors, e.g., cloudiness, precipitation, wind and heavy pollution. Experiment A was carried out in August 2015 and experiment B was carried out in July 2015. To reduce the potential interference of the variation in measurement time on the results of mobile monitoring, a two-way route mobile monitoring method was employed. Movements between measurement points were in one order on the first day and reversed on the second. The two consecutive days of data monitoring were regarded as a replication. In each experiment, six consecutive days of data monitoring, which is comprised of three 
replications, were conducted. Data were collected every $2 \mathrm{~h}$ from 8:00 to 18:00 $\mathrm{h}$ in each day, with a total of six standard time periods.

AT and RH were measured by using TES-1341 thermistor temperature tester (nominal accuracy of $0.1{ }^{\circ} \mathrm{C}$; TES, Taiwan, China), which was housed in radiation shields to avoid direct sunlight. $\mathrm{PM}_{10}$ and $\mathrm{PM}_{2.5}$ concentrations were synchronously measured using handheld DUSTMATE particle collectors (Turnkey Instruments Ltd., Northwich, UK). All instruments were placed at the center of each plot, sampling at $1.2 \mathrm{~m}$-height aboveground. Six sets of repeated measurements were made at each site, with a recording interval of $1 \mathrm{~min}$. One line transect observation took about $60 \mathrm{~min}$ for each residential area. The monitoring time was also simultaneously recorded at each measuring plot.

Considering that $\mathrm{AT}, \mathrm{RH}$ and PM concentrations may be sensitive to local climate changes during measurement time, an independent set of instruments was installed on a paved area within the study site to record local climate change from 8:00 to 18:00. Based on mathematical correction methods used in some thermal environment research [46], these data were used as a reference to correct mobile measurements to each standard time.

\subsection{Classification of Plant Community Types and Measurements of Canopy Characteristics}

In this study, plant compositions of selected plots were recorded during preinvestigation and classified into eight community types as described above. To measure canopy characteristics, CD, canopy porosity (CP), LAI and sky view factor (SVF) were selected to define the community canopy in horizontal, vertical and overall leaf volume dimensions, respectively. Within each community, five measuring points were set at the positions shown in Figure 2. All canopy measurements were conducted on a cloudy day (without strong direct solar radiation) at a $1.5 \mathrm{~m}$-height above each measuring point. The mean of these five measuring points was used to represent the CD, CP, LAI and SVF values of each community.

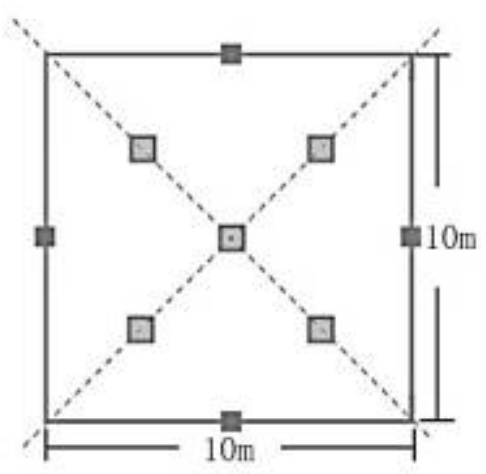

Figure 2. Schematic diagram of measuring point of CD, LAI and SVF in sample community.

(1) CD measurements: Photos were taken vertically at all measurement points within the plant community using a full-frame single-lens reflex (SLR) camera. Then, these photos were processed by Adobe Photoshop software (PS; Abode Inc., San Jose, CA, USA) and the $\mathrm{CD}$ was represented as the mean pixel ratio of the horizontal section of the canopy.

(2) CP measurements: Photos were taken horizontally toward the center of the canopy at all measurement points within the plant community using a full-frame SLR camera. After PS pretreatment, the CP was determined as the mean Photoshop pixel ratio of the vertical section of the canopy.

(3) LAI measurements: LAI values for each plant community were directly obtained using the LAI-2200 Plant Canopy Analyzer (LI-COR Biosciences, Lincoln, NE, USA). To avoid interference from surrounding obstructions, the lens cover with $30-60^{\circ}$ angle was used (depends on the surrounding environment).

(4) SVF measurements: Photos were taken vertically at all measurement points within the plant community by a full-frame SLR camera with a fisheye lens. After PS pretreatment, 
photos were imported into RayMan software [47] to further determine SVF values. An example is shown in Figure 3.

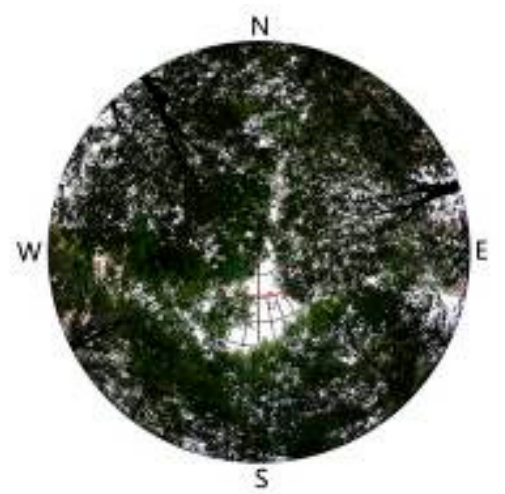

Figure 3. Example of SVF of one sample community in summer.

\subsection{Data Analysis}

In this study, for each monitoring point, the mean value of round-trip mobile data at the same time represented its observational value at this time. The averages of the six rounds of data monitoring were used to represent daily averages of $\mathrm{AT}, \mathrm{RH}, \mathrm{PM}_{10}$ and $\mathrm{PM}_{2.5}$.

One-way ANOVA and multiple comparison (Duncan's method) were carried out to examine the significant differences in microclimates and PM levels among plant communities with different compositions. Groups with identical letters are not significantly different at $\alpha=0.05$. Pearson correlation was used to examine relationships among canopy parameters, AT, RH and PM concentrations. Relationships among these variables were visualized based on non-linear curve fitting. All statistical analyses were performed using SPSS 22.0 software (IBM Corp., Armonk, NY, USA). A $p$-value $<0.05$ was regarded as being statistically significant. Non-linear fitting was performed using Origin 2017 software (OriginLab Corp., Northhampton, MA, USA).

\section{Results}

\subsection{Microclimate and Airborne Particle Levels of Different Community Types}

\subsubsection{Air Temperature and Relative Humidity}

The daily average AT (dAT) of the eight plant community types in summer are shown in Figure $4 \mathrm{a}$ with the superscript representing the result of multiple comparisons. The MTSG community had the lowest dAT $(33.58 \pm 2.04){ }^{\circ} \mathrm{C}$, followed by B-TSG $(33.95 \pm 1.91){ }^{\circ} \mathrm{C}$ and B-TG $(34.49 \pm 1.01){ }^{\circ} \mathrm{C}$. C-SG reached the highest dAT of $(38.39 \pm 1.10){ }^{\circ} \mathrm{C}$, which is dramatically higher than the minimum value of $4.81^{\circ} \mathrm{C}$. ANOVA and Duncan analysis revealed significant differences among the eight plant community types, having a $p$-value of 0.008 . As shown in Figure $4 \mathrm{~b}$, the maximum dRH was recorded in the B-TSG community $(57.41 \% \pm 4.07 \%)$, followed by M-TSG $(56.52 \% \pm 4.76 \%)$ and B-TG $(53.98 \% \pm 3.94 \%)$ community. The minimum dRH was recorded in the C-SG community $(45.59 \% \pm 4.12 \%)$. The difference between extreme values was $11.81 \%$. There were significant differences among community types $(p=0.012)$. 

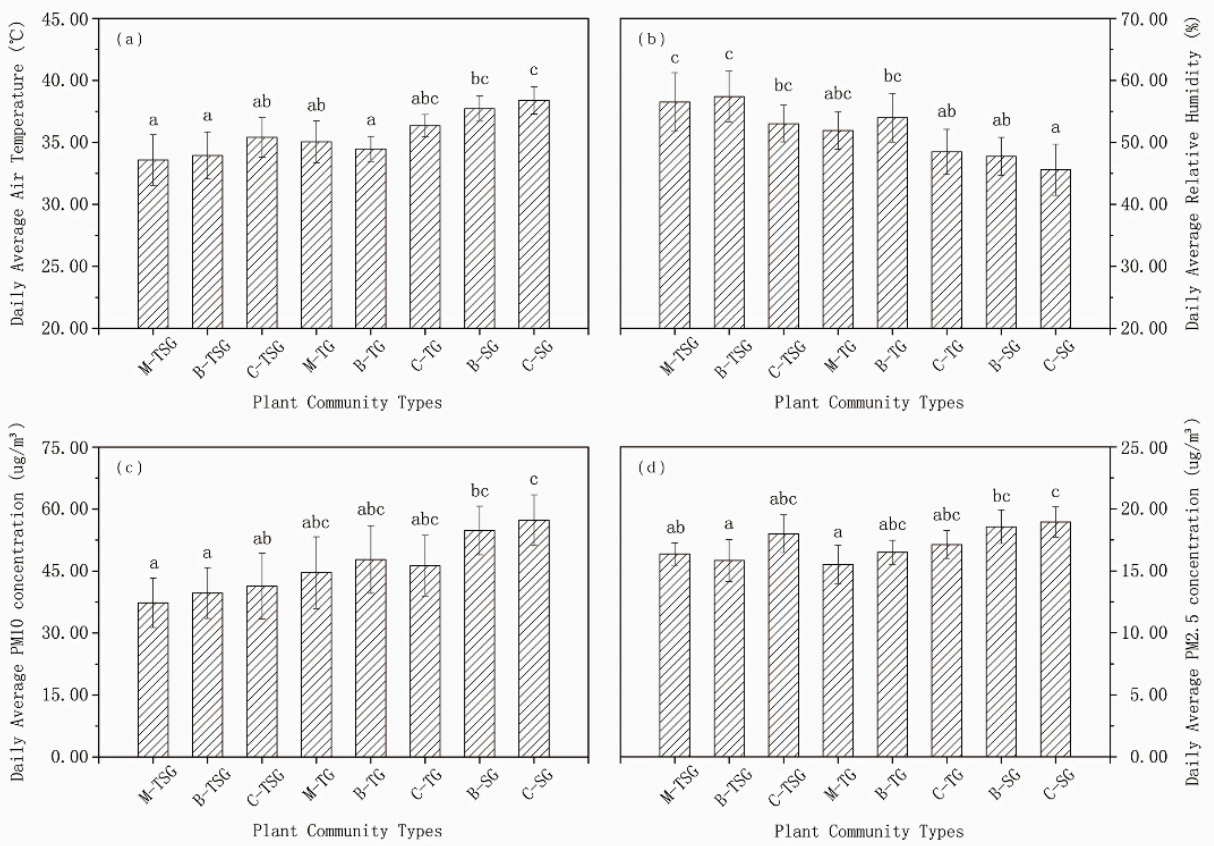

Figure 4. Daily average levels of (a) AT, (b) RH, (c) $\mathrm{PM}_{10}$ and (d) $\mathrm{PM}_{2.5}$ of different community types.

\subsubsection{Particulate Matter Concentrations}

PM concentrations shown in Figure 4c reveal that the M-TSG community had the lowest daily average $\mathrm{PM}_{10}$ concentration $\left(\mathrm{dPM}_{10}\right)$, with a value of merely $(37.31 \pm 5.98) \mu \mathrm{g} / \mathrm{m}^{3}$, followed by the $(39.67 \pm 6.16) \mu \mathrm{g} / \mathrm{m}^{3}$ B-TSG. The $(57.33 \pm 6.11) \mu \mathrm{g} / \mathrm{m}^{3} \mathrm{C}-\mathrm{SG}$ community featured the highest concentration. The daily average $\mathrm{dPM}_{10}$ of these eight plant community types ranked as follows: M-TSG < B-TSG < C-TSG < M-TG < C-TG < B-TG < B-SG $<$ C-SG, with a range of $20.02 \mu \mathrm{g} / \mathrm{m}^{3}$ and significant differences among different plant community types $(p=0.035)$. As for daily average $\mathrm{PM}_{2.5}$ levels $\left(\mathrm{dPM}_{2.5}\right)$ shown in Figure $4 \mathrm{~d}$, the difference among all eight plant community types was also significant $(p=0.042)$. M-TSG had the lowest concentration, with $\mathrm{dPM}_{2.5}$ of $(15.52 \pm 1.55) \mu \mathrm{g} / \mathrm{m}^{3}$, followed by $(15.84 \pm 1.69) \mu \mathrm{g} / \mathrm{m}^{3}$ B-TSG. $(18.57 \pm 1.36) \mu \mathrm{g} / \mathrm{m}^{3}$ B-SG and $(18.95 \pm 1.22) \mu \mathrm{g} / \mathrm{m}^{3} \mathrm{C}-\mathrm{SG}$ featured significantly higher concentrations than others, while the difference in extreme values was $3.43 \mu \mathrm{g} / \mathrm{m}^{3}$.

\subsection{Response of Microclimate and Airborne Particle Levels to Plant Community Canopy Characteristics}

The canopy characteristics and the daily average AT, RH, $\mathrm{PM}_{10}$ and $\mathrm{PM}_{2.5}$ values of the nine plant communities in experiment $\mathrm{B}$ are, respectively, shown in Tables 4 and 5 . To examine the effects of canopy characteristics on microclimate and airborne particle levels, we analyzed the relationships of $\mathrm{AT}, \mathrm{RH}, \mathrm{PM}_{10}$ and $\mathrm{PM}_{2.5}$ levels with canopy parameters by calculating Pearson's correlation coefficients (cc) as shown in Table 6.

Table 4. Canopy parameters of the sampling community.

\begin{tabular}{ccccc}
\hline No. & CD (\%) & CP (\%) & LAI & SVF (\%) \\
\hline D1 & 44.879 & 70.864 & 1.322 & 0.476 \\
D2 & 57.311 & 57.192 & 1.506 & 0.324 \\
D3 & 67.264 & 63.336 & 1.714 & 0.412 \\
D4 & 71.369 & 57.968 & 2.356 & 0.238 \\
D5 & 75.840 & 54.686 & 2.268 & 0.249 \\
D6 & 77.589 & 51.036 & 2.540 & 0.185 \\
D7 & 82.392 & 53.866 & 2.932 & 0.147 \\
D8 & 89.585 & 43.706 & 3.294 & 0.112 \\
D9 & 92.280 & 42.213 & 2.968 & 0.095 \\
\hline
\end{tabular}


Table 5. Daily average level of $\mathrm{AT}, \mathrm{RH}, \mathrm{PM}_{10}$ and $\mathrm{PM}_{2.5}$ within the sampling community.

\begin{tabular}{|c|c|c|c|c|}
\hline No. & $\begin{array}{l}\text { dAT } \\
\left({ }^{\circ} \mathrm{C}\right)\end{array}$ & $\begin{array}{c}\text { dRH } \\
(\%)\end{array}$ & $\begin{array}{c}\mathrm{dPM}_{10} \\
\left(\mathrm{ug} / \mathrm{m}^{3}\right)\end{array}$ & $\begin{array}{l}\mathrm{dPM}_{2.5} \\
\left(\mathrm{ug} / \mathrm{m}^{3}\right)\end{array}$ \\
\hline D1 & 31.218 & 49.666 & 109.923 & 44.565 \\
\hline D2 & 30.977 & 51.415 & 107.745 & 41.593 \\
\hline D3 & 31.091 & 50.228 & 104.441 & 42.715 \\
\hline D4 & 30.829 & 52.922 & 103.083 & 39.040 \\
\hline D5 & 30.286 & 54.053 & 105.297 & 37.943 \\
\hline D6 & 29.724 & 53.746 & 94.929 & 35.732 \\
\hline D7 & 30.391 & 52.569 & 100.944 & 38.764 \\
\hline D8 & 29.540 & 55.932 & 98.622 & 40.678 \\
\hline D9 & 29.471 & 54.479 & 101.549 & 40.198 \\
\hline
\end{tabular}

Table 6. Correlation coefficients between community canopy parameters and microclimate and PM factors.

\begin{tabular}{|c|c|c|c|c|c|c|c|c|}
\hline \multirow{2}{*}{ No. } & \multicolumn{2}{|c|}{ CD } & \multicolumn{2}{|c|}{$\mathrm{CP}$} & \multicolumn{2}{|c|}{ LAI } & \multicolumn{2}{|c|}{ SVF } \\
\hline & cc & sig. & cc & sig. & cc & sig. & cc & sig. \\
\hline dAT & $-0.874^{* *}$ & 0.002 & $0.930 * *$ & 0.000 & $-0.867^{* *}$ & 0.002 & $0.885^{* *}$ & 0.002 \\
\hline $\mathrm{dRH}$ & $0.865^{* *}$ & 0.003 & $-0.917^{* *}$ & 0.001 & $0.880^{* *}$ & 0.002 & $-0.902^{* *}$ & 0.001 \\
\hline $\mathrm{dPM}_{10}$ & $-0.769 *$ & 0.015 & 0.711 * & 0.032 & $-0.788^{*}$ & 0.012 & $0.762 *$ & 0.017 \\
\hline $\mathrm{dPM}_{2.5}$ & -0.591 & 0.094 & 0.551 & 0.124 & -0.570 & 0.109 & 0.671 * & 0.048 \\
\hline
\end{tabular}

Note: cc refers to correlation coefficient; sig. refers to significance, ${ }^{*}$ and ${ }^{* *}$ represent significant level.

\subsubsection{Air Temperature and Relative Humidity}

Results shown in Table 6 and Figure $5 \mathrm{a}, \mathrm{b}$ suggest that $\mathrm{CD}$ had a strong negative correlation with dAT ( $\mathrm{cc}=-0.874)$, but was positively correlated with $\mathrm{dRH}(\mathrm{cc}=-0.865)$. Both correlations reached high significance levels (sig. < 0.01). With increasing CD, dAT gradually decreased, while $\mathrm{dRH}$ increased. As $\mathrm{CD}$ increased to about $65 \%$, the plant community had a cooling effect, although dAT declined very slightly. Once the CD was over $70 \%$, the decline in dAT was obvious. This indicates that $65 \%-70 \%$ may be a key $\mathrm{CD}$ threshold to affect ambient AT. With increasing $\mathrm{CD}$, the change rate of $\mathrm{dRH}$ remained stable, showing a quasilinear increase, with no indication of a critical threshold.

$\mathrm{CP}$ was found to be positively correlated with $\mathrm{dAT}$, but negatively correlated with $\mathrm{dRH}$, with cc values of 0.930 and -0.917 , respectively (sig. < 0.01 , Table 6). The dAT changed less dramatic when $\mathrm{CP}$ fell below $48 \%$ (Figure 5c), while dramatic AT changes were found between $50 \%-60 \% \mathrm{CP}$, suggesting that plant communities with $\mathrm{CP}$ in this interval had marked cooling effects. However, when the community canopy became too porous in the horizontal direction, with $\mathrm{CP}$ larger than $60 \%$, the cooling effect was extremely limited. The correlation between $\mathrm{CP}$ and $\mathrm{dRH}$ shown in Figure $5 \mathrm{~d}$ is quasilinear. With increasing $\mathrm{CP}$, the reduction in $\mathrm{dRH}$ decreased (CP around 57\%), although a critical threshold was not apparent.

The dAT decreased while the dRH increased significantly with increasing LAI, as indicated by the results shown in Table 6 and Figure 5e,f. Both parameters were correlated at a high level of significance (sig. $<0.01$ ), with cc values of -0.905 and 0.867 , respectively. With increasing LAI, the reduction in dAT changed slightly. In contrast, the $\mathrm{dRH}$ increased in a steady quasilinear trend. No thresholds were apparent for AT and RH related to this canopy characteristic.

In contrast, a significant positive relationship between SVF and dAT was observed ( $c c=0.885$, sig. $<0.01$ ). Lower SVF led to lower dAT. This trend suggests that when the SVF increased within the range $0.10-0.25$, the increment in $\mathrm{dAT}$ was slightly higher than that when SVF was over 0.25. However, this threshold was not well defined. Meanwhile, the $\mathrm{dRH}$ decreased significantly with increasing SVF $(\mathrm{cc}=-0.902$, sig. $<0.01)$. The relationship between SVFs and dRH was also quasilinear. 

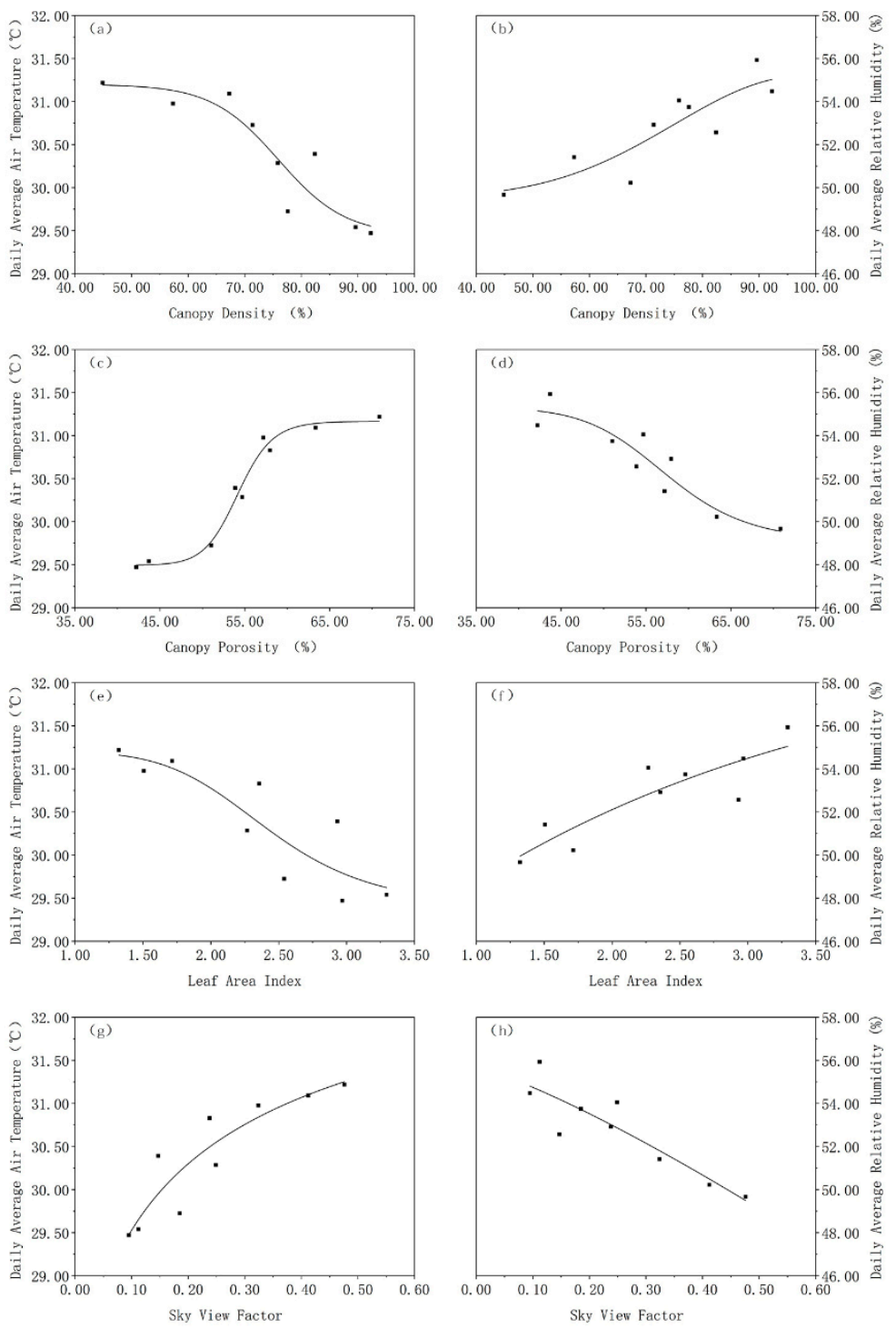

Figure 5. Non-linear fitting relationship between: (a) canopy density and daily average AT; (b) canopy density and daily average RH; (c) canopy porosity and daily average AT; (d) canopy porosity and daily average $\mathrm{RH}$; (e) leaf area index and daily average AT; (f) leaf area index and daily average $\mathrm{RH}$; (g) sky view factor and daily average AT; (h) sky view factor and daily average RH.

\subsubsection{Particulate Matter Concentrations}

The results in Table 6 and Figure 6 a show that the $\mathrm{dPM}_{10}$ was negatively correlated with $\mathrm{CD}$ ( $\mathrm{cc}=-0.769$, sig. $<0.05)$. With increasing $\mathrm{CD}$, the $\mathrm{dPM}_{10}$ decreased significantly without obvious fluctuation. However, when $\mathrm{CD}$ increased to $60 \%-75 \%$, the $\mathrm{dPM}_{10}$ reduction increased significantly. Once the $\mathrm{CD}$ exceeded $80 \%$, the reduction slowed down again. Interestingly, no significant relationship was detected between $\mathrm{CD}$ and $\mathrm{dPM}_{2.5}$ (sig. > 0.05). From Figure $6 \mathrm{~b}$, the $\mathrm{dPM}_{2.5}$ first showed an obvious decrease, but as $C D$ increased to around $78 \%, \mathrm{dPM}_{2.5}$ increased instead. This indicates that high canopy density is not necessarily conducive to reducing $\mathrm{PM}_{2.5}$. From the fitting trend in Figure $6 \mathrm{~b}, 75 \%$ was identified as the key $\mathrm{CD}$ threshold for effective $\mathrm{PM}_{2.5}$ reduction. 

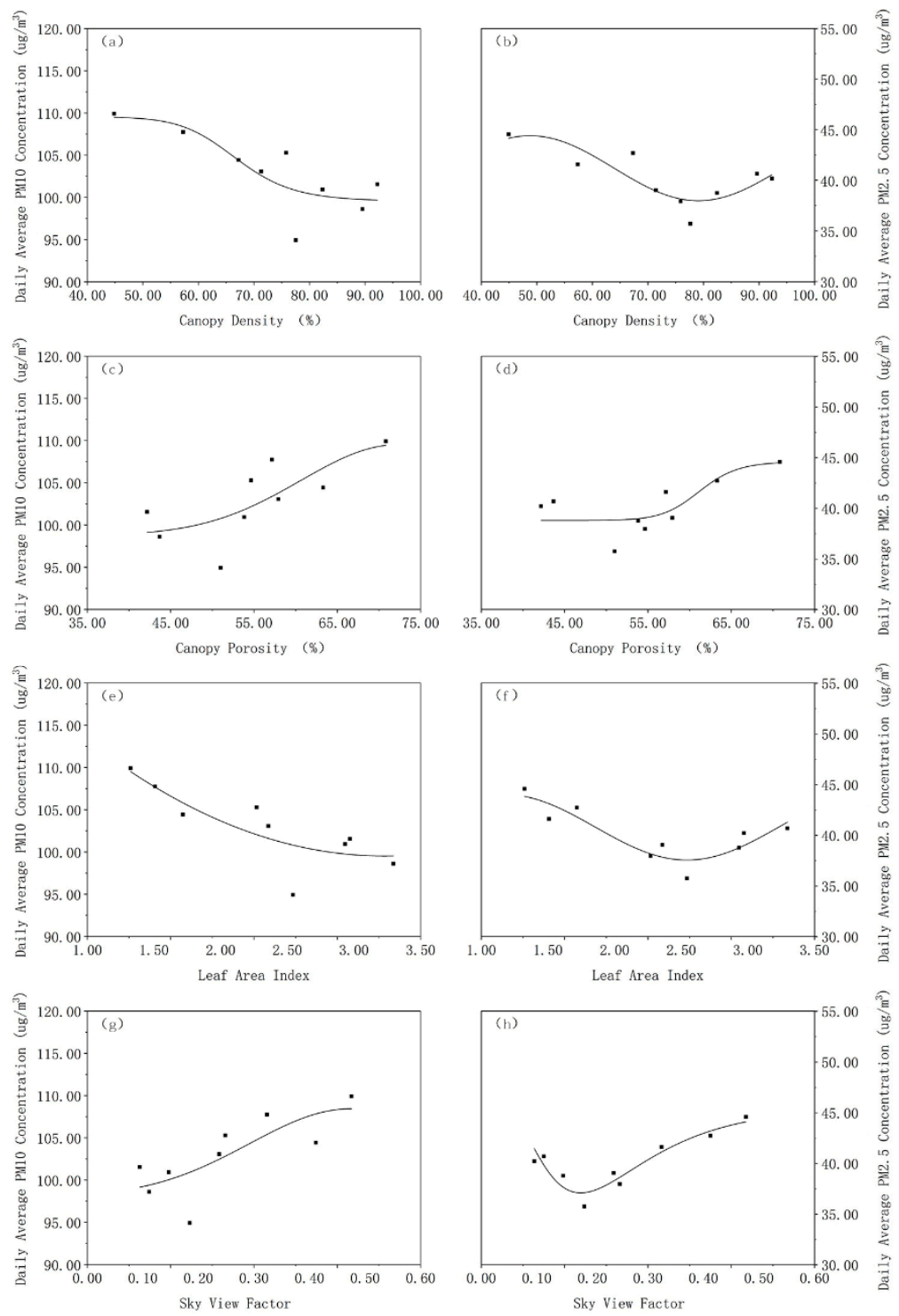

Figure 6. Non-linear fitting relationship between: (a) canopy density and daily average $\mathrm{PM}_{10}$; (b) canopy density and daily average $\mathrm{PM}_{2.5}$; (c) canopy porosity and daily average $\mathrm{PM}_{10}$; (d) canopy porosity and daily average $\mathrm{PM}_{2.5}$; (e) leaf area index and daily average $\mathrm{PM}_{10}$; (f) leaf area index and daily average $\mathrm{PM}_{2.5}$; (g) sky view factor and daily average $\mathrm{PM}_{10}$; (h) sky view factor and daily average $\mathrm{PM}_{2.5}$.

The $\mathrm{dPM}_{10}$ values showed a significant positive correlation with $\mathrm{CP}$ (sig. $\left.<0.05\right)$, with a cc value of 0.711 (Table 6). With increasing $\mathrm{CP}, \mathrm{dPM}_{10}$ increased (Figure $6 \mathrm{c}$ ). The response of $\mathrm{dPM}_{10}$ to the change in $\mathrm{CP}$ did not fluctuate significantly. With higher canopy porosity in the horizontal direction, the interception and filtration effects on $\mathrm{PM}_{10}$ became weaker. There was no obvious inflection point to this fitting trend. The correlation between $\mathrm{dPM}_{2.5}$ and CP was insignificant (sig. > 0.05). As CP gradually increased, the $\mathrm{dPM}_{2.5}$ slightly increased (Figure $6 \mathrm{~d}$ ). Once $\mathrm{CP}$ reached $55 \%$, the growth rate of $\mathrm{dPM}_{2.5}$ accelerated. This indicates that $\mathrm{CP}$ values below $55 \%$ are beneficial to the absorption of $\mathrm{PM}_{2.5}$, but once the $\mathrm{CP}$ exceeds $55 \%$, the sparse canopy cannot effectively reduce fine particles.

The $\mathrm{dPM}_{10}$ concentration was negatively correlated with LAI (sig. $<0.05$, $\mathrm{cc}=-0.788$ ). As LAI increased, the $\mathrm{dPM}_{10}$ decreased, with no obvious fluctuation. Once LAI exceeded 2.8 , still to increase, the decline in $\mathrm{dPM}_{10}$ slowed. Therefore, a LAI value of 2.8 may be the threshold for community canopy to effectively reduce $\mathrm{PM}_{10}$. There was no significant correlation between $\mathrm{dPM}_{2.5}$ and LAI (sig. > 0.05). With increasing LAI, $\mathrm{dPM}_{2.5}$ had 
a U-shaped trend, first decreasing and then increasing, yielding a critical threshold of around 2.50 .

SVF had a significant positive effect on $\mathrm{dPM}_{10}$ (Table 6), with a cc value of 0.762 (sig. < 0.05). Higher SVF lead to higher $\mathrm{dPM}_{10}$, with an quasilinear trend (Figure $6 \mathrm{~g}$ ). The positive relationship between $\mathrm{dPM}_{2.5}$ and SVF was also significant (sig. $<0.05, \mathrm{cc}=0.671$ ). The trend showed a V-shape with the ascending segment obviously larger than the descending one, and the valley located around 0.18 . As SVF decreased from a higher level, the $\mathrm{dPM}_{2.5}$ decreased rapidly. Once SVF dropped to 0.18 , the $\mathrm{dPM}_{2.5}$ started to rise again. This indicates that although low SVF enhances the diffusion and attenuation of fine particles, high SVF sustains fine particles under the canopy.

\section{Discussion}

The effects of different plant community compositions and canopy characteristics on $\mathrm{AT}, \mathrm{RH}$ and air particle levels have received increasing attention recently because the cooling, humidifying and particle-detaining abilities differ greatly among tree species [48,49]. This means that plant communities, comprised of different plant species, have variable potentials to regulate heat and pollution. Meanwhile, the regulatory effects of plant communities on environmental factors do not equal a simple superposition of the regulatory capacities of individual plants. Instead, the canopy structures, reflecting the overall leaf volume and geometric shape of the plant community, have important impacts on energy conversion and airflow beneath the canopy, affecting microclimate and airborne particle levels [50]. Based on this, our investigation focused on the effects of community composition and canopy structure on microclimate and airborne particle levels.

\subsection{Effects of Plant Community Composition on Microclimate and Airborne Particle Levels}

Some previous studies have found that there are differences between conifers and broad-leaved plants in regulating microclimate [51,52]. Compared with plant communities composed solely of coniferous or broad-leaved plants, mixed-composition plant communities have better cooling and humidifying effects. The coniferous communities perform remarkably well at shading and cooling, while the broad-leaved communities often produce an excellent humidifying effect. In addition to species composition, the hierarchical structure of the plant community also affects the overall biomass and canopy characteristics of the community. Zhu et al. [53] reported that the cooling and humidifying effects of turf communities are not significant. In contrast, tree-shrub-grass communities have a large leaf area, and can provide a remarkable microclimate effect. Tree-grass communities also maintain strong permeability under sufficient leaf amount, which is conducive to the air circulation under their canopies, especially in breezy weather, demonstrating an outstanding cooling effect. In this study, the daily average AT and RH of the different community types were significantly different. The cooling and humidifying effects of the M-TSG and B-TSG communities were excellent compared with the other types. This is precisely because these two community types have more leaves and higher canopy coverage, resulting in stronger transpiration, and a greater capacity to intercept and absorb solar radiation. Previous researchers have drawn similar conclusions [54,55].

Similarly, for airborne particles, the composition of the plant community determines its regulatory effect on different-sized PM. There are reports of conifers having smaller leaf area but denser canopies which may intercept airborne particles effectively. Moreover, some pine species secrete mucus, making it difficult for adhering particles to re-enter the atmosphere [55,56]. Apparently, trees are the main agents for removal of air particles in green spaces, given their dense canopies and large total leaf areas, which enhance their dust retention capacities $[23,57,58]$. In this study, we found that the M-TSG community, with abundant leaves and a mixed structure, reduced $\mathrm{PM}_{10}$ most greatly. However, as for $\mathrm{PM}_{2.5}$, although plant communities with scarce leaves were not conducive to the absorption of fine particles, outward diffusion of $\mathrm{PM}_{2.5}$ was hindered when the hierarchical structure was too complex and dense. In addition, some studies have found that some organic volatiles 
released by conifers can be converted into secondary aerosols, forming $\mathrm{PM}_{2.5}$ and other fine particles [59]. Therefore, having sufficient leaf area, internal airflow permeability and moderate coniferous components make the M-TG community the most efficient at reducing $\mathrm{PM}_{2.5}$. Differences in $\mathrm{dPM}_{10}$ among the eight community types were more pronounced than those for $\mathrm{dPM}_{2.5}$, indicating that community composition has a greater influence on coarse particles than on fine particles.

\subsection{Critical Thresholds of Plant Community Canopy's Regulating Effects on Microclimate and Airborne Particle Levels}

Canopy characteristics affect the thermal and airborne-particle regulation service of a plant community. Based on remote sensing data and field survey, Hardin [33] found that the cooling effect of urban forests was significantly positively correlated with LAI. Srivanit and Hokao [35] pointed out that $\mathrm{CD}$ is an important factor affecting the cooling effect related to urban forests. Peters and Mcfadden [34] also advocated that the AT within plant communities was significantly related to community CD and LAI. Similar conclusions were drawn in this study. The dAT within the community was significantly negatively correlated with CD and LAI, but positively correlated with CP and SVF. In contrast, $\mathrm{dRH}$ showed the reverse trends with these attributes. Generally, the density of the plant community canopy in the vertical direction $(\mathrm{CD}, \mathrm{SVF})$ determines the amount of solar radiation intercepted and absorbed, while the porosity $(\mathrm{CP})$ in the horizontal direction affects the air exchange between the plant community and its surroundings. When the community canopy became too dense in the horizontal direction, it hindered air circulation under the canopy and slowed down heat loss. LAI reflects the total leaf amount of the community, which determines the amount of transpiration and shade cast. These all affect the heat and water conversion inside and outside the community, and therefore affect AT and RH. Hence, plant communities with high CD and LAI but low CP and SVF resulted in greater cooling and humidifying effects.

In our study, several specific inflection points were found in non-linear responses between some canopy characteristics and dAT and dRH. Plant communities with CD over $65 \%-70 \%$ and $\mathrm{CP}$ below $60 \%$ had outstanding cooling effects. As a plant community's humidification effects mainly depend on transpiration, its relations with canopy characteristics were basically linear. As CD and LAI increased, and CP and SVF decreased, RH increased steadily, showing no critical threshold. A few scholars have recently attempted to explore critical thresholds of vegetation canopy attributes affecting microclimate. Zhu et al. [53] found that when CD ranged from $10 \%$ to $31 \%$, the community had a slight cooling and humidifying effect. This effect became significant once values exceeded $44 \%$, and stabilized at $67 \%$. Tang et al. [39] advocated that the cooling intensity of a plant community was linearly and positively correlated with CD. Every $10 \%$ increase in CD caused the cooling intensity to increase by $0.5^{\circ} \mathrm{C}$. In contrast, there was a non-linear positive correlation between LAI and the cooling intensity of the community. Once LAI increased within the range of $0.23-2.30$, the cooling intensity increased rapidly. There is still much to explore in this field and more research is needed.

The $\mathrm{dPM}_{10}$ and $\mathrm{dPM}_{2.5}$ had variable relationships with community $\mathrm{CD}, \mathrm{CP}, \mathrm{LAI}$ and SVF. Generally, when air carrying PM passes through the community canopy, large-sized particles are more likely to be intercepted and deposited on the surfaces of branches, leaves and stems [60]. Therefore, when communities have higher CD and LAI, but lower CP and SVF values, this creates a canopy structure with a larger amount of branches and leaves in both horizontal and vertical directions, allowing it to intercept more coarse particles like $\mathrm{PM}_{10}$. In contrast, Liu et al. [37] found that $\mathrm{PM}_{2.5}$ level was positively correlated with $\mathrm{CD}$, LAI and average tree diameter (DBH), but negatively correlated with average tree height, forest land area, herbaceous coverage and height. In this study, most responses of $\mathrm{dPM}_{2.5}$ to community canopy structure were non-linear, with critical inflection points, resulting in few significant correlations. This may be related to the dependence of the attenuation of fine particles on outward diffusion dilution. Therefore, when the community canopy is too sparse, it is not conducive to the interception and absorption of $\mathrm{PM}_{2.5}$. However, 
dense canopies will not only hinder the diffusion of $\mathrm{PM}_{2.5}$ into the upper atmosphere along with turbulent air flow, but weaken the Brownian motion of particles under low temperature and high humidity conditions, which could even increase their concentration due to the moisture absorption and condensation of fine particles. Compared with $\mathrm{dPM}_{10}$, the response of $\mathrm{dPM}_{2.5}$ to community canopy structure is more complex. Janhäll [30] mentioned that vegetation barriers were suggested to be dense enough to provide a large depositional surface area, but porous enough to ensure air infiltration and upward diffusion of particles. Similar conjectures can be made based on the results of this study.

To date, only a few scholars have reported critical thresholds of plant community canopy characteristics affecting air particle levels. Yin et al. [56] considered that the best $\mathrm{CD}$ and $\mathrm{CP}$ values for plant communities to reduce total suspended particulates (TSP) were $70 \%-85 \%$ and $25 \%-33 \%$, respectively. In our study, communities with CD values above $65 \%-70 \%$ and LAI values below 2.8 had higher reduction effects on $\mathrm{PM}_{10}$. For $\mathrm{PM}_{2.5}$, the greatest reductions occurred for CD, CP, LAI and SVF values of $75 \%-78 \%, 55 \%, 2.30-2.50$ and 0.18 , respectively. Our results clearly have some overlap with Yin's conclusions.

Canopy structure is an important factor affecting the thermal and air particle regulatory services of plant communities. A previous study recorded strong associations between air pollutants and UHI effect during certain seasons (i.e., winter and autumn) [32]. Therefore, constructing plant communities with good regulatory effects on both microclimate and air particle pollution is an economical and effective way to improve urban environments. In this study, mixed TSG and TG communities with CD, CP, LAI and SVF values of $75 \%, 55 \%, 2.5$ and 0.18 , respectively, produced noticeable positive effects on both microclimate and air particle levels.

In general, this work focused on the impacts of the composition and canopy characteristics of plant communities on microclimate and airborne particles in Beijing and quantified the critical thresholds of plant community canopy characteristics. This research may guide future urban green spaces' construction aiming to improve the thermal environment and reduce air pollution. However, this study also has some limitations. Firstly, although the study area and selected plant communities are typical in urban green-space in Beijing, limited by the monitoring conditions, the number of samples is limited. Secondly, it must be noted that the critical thresholds of canopy structure reported here may only be applicable to our study area, and could not be validated as general conclusions. Future research is urgently needed to support and corroborate our results in future.

\section{Conclusions}

In summer, significant differences existed in daily $\mathrm{AT}, \mathrm{RH}, \mathrm{PM}_{10}$ and $\mathrm{PM}_{2.5}$ levels among eight plant community types. The M-TSG community had the strongest cooling and $\mathrm{PM}_{10}$ reduction effects; the B-TSG community had the best humidifying effect; and the M-TG community was most effective in reducing $\mathrm{PM}_{2.5}$. dAT and $\mathrm{dPM}_{10}$ were significantly negatively correlated with CD and LAI, while positively related with CP and SVF, while these correlations were opposite for $\mathrm{dRH}$. The response of $\mathrm{dPM}_{2.5}$ to various canopy structures was complex, featuring multiple non-linear relations. Critical thresholds were found in some cases. Plant communities with $\mathrm{CD}$ greater than $65 \%-70 \%$ and $\mathrm{CP}$ below $60 \%$ had a significant cooling effect. No critical threshold was found for the humidifying effect. Plant communities with CD ranging $60 \%-75 \%$ and LAI close to but no more than 2.8 had excellent $\mathrm{PM}_{10}$ reduction effects. Plant communities featuring $75 \%-78 \%$, 55\%, 2.30-2.50 and 0.18 CD, CP, LAI and SVF, respectively, had pronounced $\mathrm{PM}_{2.5}$ reduction effect. Overall, mixed TSG or TG communities with about 75\% CD, 55\% CP, $2.5 \mathrm{LAI}$ and 0.18 SVF perform most noticeably both microclimate and air particle regulation services.

Author Contributions: Conceptualization, S.F., L.D.; funding acquisition, L.D.; project administration, L.D.; data acquisition, S.F.; formal analysis, S.F., M.Z., Y.L., K.L.; drafting the manuscript, S.F., L.D.; revising the manuscript critically for important intellectual content, S.F., L.D. All authors have read and agreed to the published version of the manuscript. 
Funding: This work was supported by Beijing Municipal Science and Technology Project (D171100 007117001).

Institutional Review Board Statement: Not applicable.

Informed Consent Statement: Not applicable.

Data Availability Statement: Not applicable.

Acknowledgments: This research was funded by Beijing Municipal Science and Technology Project: Establishing Evaluation System for Ecological Function of Multi-scale Green Spaces in the Northern Urban Area (D171100007117001). We would like to thank Sijia Wu, Yilun Li, Kun Li, Mengyuan Zhang, Jing Han, Rui Jing and Fan Wu for their support in the field work and data processing. We sincerely thank the anonymous reviewers for their valuable comments.

Conflicts of Interest: The authors declare no conflict of interest.

\section{References}

1. Grimm, N.B.; Faeth, S.H.; Golubiewski, N.E.; Redman, C.L.; Wu, J.; Bai, X.; Briggs, J.M. Global Change and the Ecology of Cities. Science 2008, 319, 756-760. [CrossRef] [PubMed]

2. King, K.L.; Johnson, S.; Kheirbek, I.; Lu, J.W.; Matte, T. Differences in magnitude and spatial distribution of urban forest pollution deposition rates, air pollution emissions, and ambient neighborhood air quality in New York City. Landsc. Urban Plan. 2014, 128, 14-22. [CrossRef]

3. Rizwan, A.M.; Dennis, L.Y.; Liu, C. A review on the generation, determination and mitigation of Urban Heat Island. J. Environ. Sci. 2008, 20, 120-128. [CrossRef]

4. Beijing Municipal Environmental Protection Bureau. Air Quality Status in Beijing 2019. 2020. Available online: http://sthjj. beijing.gov.cn/bjhrb/index/xxgk69/sthjlyzwg/1718880/1718889/1725050/index.html (accessed on 23 January 2020).

5. Marando, F.; Salvatori, E.; Sebastiani, A.; Fusaro, L.; Manes, F. Regulating Ecosystem Services and Green Infrastructure: Assessment of Urban Heat Island effect mitigation in the municipality of Rome, Italy. Ecol. Model. 2019, 392, 92-102. [CrossRef]

6. Schwarz, N.; Schlink, U.; Franck, U.; Großmann, K. Relationship of land surface and air temperatures and its implica-tions for quantifying urban heat island indicators-An application for the city of Leipzig (Germany). Ecol. Ind. 2012, 18, 693-704. [CrossRef]

7. Voogt, J.; Oke, T. Thermal remote sensing of urban climates. Remote Sens. Environ. 2003, 86, 370-384. [CrossRef]

8. Nowak, D.J.; Hirabayashi, S.; Bodine, A.; Greenfield, E. Tree and forest effects on air quality and human health in the United States. Environ. Pollut. 2014, 193, 119-129. [CrossRef]

9. Giridharan, R.; Lau, S.; Ganesan, S.; Givoni, B. Urban design factors influencing heat island intensity in high-rise high-density environments of Hong Kong. Build. Environ. 2007, 42, 3669-3684. [CrossRef]

10. Gober, P.; Brazel, A.; Quay, R.; Myint, S.; Grossman-Clarke, S.; Miller, A.; Rossi, S. Using Watered Landscapes to Manipulate Urban Heat Island Effects: How Much Water Will It Take to Cool Phoenix? J. Am. Plan. Assoc. 2009, 76, 109-121. [CrossRef]

11. Zhao, X.; Liu, J.; Bu, Y. Quantitative Analysis of Spatial Heterogeneity and Driving Forces of the Thermal Environment in Urban Built-Up Areas: A Case Study in Xi'an, China. Sustainability 2021, 13, 1870. [CrossRef]

12. Li, L.; Wang, W.; Feng, J.; Zhang, D.; Li, H.; Gu, Z.; Wang, B.; Sheng, G.; Fu, J. Composition, source, mass closure of PM2.5 aerosols for four forests in eastern China. J. Environ. Sci. 2010, 22, 405-412. [CrossRef]

13. Masiol, M.; Squizzato, S.; Rampazzo, G.; Pavoni, B. Source apportionment of PM2.5 at multiple sites in Venice (Italy): Spatial variability and the role of weather. Atmos. Environ. 2014, 98, 78-88. [CrossRef]

14. Rooney, M.S.; Arku, R.E.; Dionisio, K.L.; Paciorek, C.; Friedman, A.B.; Carmichael, H.; Zhou, Z.; Hughes, A.F.; Vallarino, J.; Agyei-Mensah, S.; et al. Spatial and temporal patterns of particulate matter sources and pollution in four communities in Accra, Ghana. Sci. Total Environ. 2012, 435-436, 107-114. [CrossRef]

15. Garcia, J.N.P.M.; Cerdeira, R.S.D.S.; Tavares, N.A.; Coelho, L.M.R. Studying street geometry influence in PM10 concentration. Int. J. Environ. Pollut. 2012, 50, 283. [CrossRef]

16. Gomez-Martinez, F.; Beurs, K.M.D.; Koch, J.; Widener, J. Multi-Temporal Land Surface Temperature and Vegetation Green-ness in Urban Green Spaces of Puebla, Mexico. Land 2021, 10, 155. [CrossRef]

17. Hoek, G.; Beelen, R.; Hoogh, K.; Vienneau, D.; Gulliver, J.; Fischer, P.; Briggs, D. A Review of Land-use Regression Models to Assess Spatial Variation of Outdoor Air Pollution. Atmos. Environ. 2008, 42, 7561-7578. [CrossRef]

18. Zhai, L.; Zou, B.; Fang, X.; Luo, Y.; Wan, N.; Li, S. Land Use Regression Modeling of PM2.5 Concentrations at Optimized Spatial Scales. Atmosphere 2016, 8, 1. [CrossRef]

19. Ng, E.; Chen, L.; Wang, Y.; Yuan, C. A study on the cooling effects of greening in a high-density city: An experience from Hong Kong. Build. Environ. 2012, 47, 256-271. [CrossRef]

20. Nowak, D.J.; Crane, D.E.; Stevens, J.C. Air pollution removal by urban trees and shrubs in the United States. Urban For. Urban Green. 2006, 4, 115-123. [CrossRef] 
21. Yin, S.; Cai, J.; Chen, L.; Shen, Z.; Zou, X.; Wu, D.; Wang, W. Effects of vegetation status in urban green spaces on particles removal in a canyon street atmosphere. Acta Ecol. Sin. 2007, 27, 4590-4595.

22. Yin, S.; Shen, Z.; Zhou, P.; Zou, X.; Che, S.; Wang, W. Quantifying air pollution attenuation within urban parks: An experimental approach in Shanghai, China. Environ. Pollut. 2011, 159, 2155-2163. [CrossRef]

23. Litschke, T.; Kuttler, W. On the reduction of urban particle concentration by vegetation a review. Meteorol. Z. 2008, 17, 229-240. [CrossRef]

24. Onishi, A.; Cao, X.; Ito, T.; Shi, F.; Imura, H. Evaluating the potential for urban heat-island mitigation by greening parking lots. Urban For. Urban Green. 2010, 9, 323-332. [CrossRef]

25. Paoletti, E.; Bardelli, T.; Giovannini, G.; Pecchioli, L. Air quality impact of an urban park over time. Procedia Environ. Sci. 2011, 4, 10-16. [CrossRef]

26. Dimoudi, A.; Nikolopoulou, M. Vegetation in the urban environment: Microclimatic analysis and benefits. Energy Build. 2003, 35, 69-76. [CrossRef]

27. Georgi, J.N.; Dimitriou, D. The contribution of urban green spaces to the improvement of environment in cities: Case study of Chania, Greece. Build. Environ. 2010, 45, 1401-1414. [CrossRef]

28. Oliveira, S.; Andrade, H.; Vaz, T. The cooling effect of green spaces as a contribution to the mitigation of urban heat: A case study in Lisbon. Build. Environ. 2011, 46, 2186-2194. [CrossRef]

29. Cavanagh, J.-A.E.; Zawar-Reza, P.; Wilson, J.G. Spatial attenuation of ambient particulate matter air pollution within an urbanised native forest patch. Urban For. Urban Green. 2009, 8, 21-30. [CrossRef]

30. Janhäll, S. Review on urban vegetation and particle air pollution-Deposition and dispersion. Atmos. Environ. 2015, 105, 130-137. [CrossRef]

31. Fowler, D.; Skiba, U.; Nemitz, E.; Choubedar, F.; Branford, D.; Donovan, R.; Rowland, P. Measuring Aerosol and Heavy Metal Deposition on Urban Woodland and Grass Using Inventories of $210 \mathrm{~Pb}$ and Metal Concentrations in Soil. Water Air Soil Pollut. Focus 2004, 4, 483-499. [CrossRef]

32. Skelhorn, C.; Lindley, S.; Levermore, G. The impact of vegetation types on air and surface temperatures in a temperate city: A fine scale assessment in Manchester, UK. Landsc. Urban Plan. 2014, 121, 129-140. [CrossRef]

33. Hardin, P.J.; Jensen, R.R. The effect of urban leaf area on summertime urban surface kinetic temperatures: A Terre Haute case study. Urban For. Urban Green. 2007, 6, 63-72. [CrossRef]

34. Peters, E.B.; McFadden, J.P. Influence of seasonality and vegetation type on suburban microclimates. Urban Ecosyst. 2010, 13, 443-460. [CrossRef]

35. Srivanit, M.; Hokao, K. Evaluating the cooling effects of greening for improving the outdoor thermal environment at an institutional campus in the summer. Build. Environ. 2013, 66, 158-172. [CrossRef]

36. Givoni, B. Impact of planted areas on urban environmental quality: A review. Atmos. Environ. Part B Urban Atmos. 1991, 25, 289-299. [CrossRef]

37. Liu, X.; Yu, X.; Zhang, Z. PM2.5 Concentration Differences between Various Forest Types and Its Correlation with Forest Structure. Atmosphere 2015, 6, 1801-1815. [CrossRef]

38. Setälä, H.; Viippola, V.; Rantalainen, A.-L.; Pennanen, A.; Yli-Pelkonen, V. Does urban vegetation mitigate air pollution in northern conditions? Environ. Pollut. 2013, 183, 104-112. [CrossRef]

39. Tang, Z.; Ren, Z.; Zheng, H.; He, X. Cooling effects of urban forest community structure. Chinese J. Appl. Ecol. 2017, 28, 2823-2830. [CrossRef]

40. Ngarambe, J.; Joen, S.J.; Han, C.-H.; Yun, G.Y. Exploring the relationship between particulate matter, $\mathrm{CO}, \mathrm{SO}_{2}, \mathrm{NO}_{2}, \mathrm{O}_{3}$ and urban heat island in Seoul, Korea. J. Hazard. Mater. 2021, 403, 123615. [CrossRef]

41. Sebastiani, A.; Marando, F.; Manes, F. Mismatch of regulating ecosystem services for sustainable urban planning: PM10 removal and urban heat island effect mitigation in the municipality of Rome (Italy). Urban For. Urban Green. 2021, 57, 126938. [CrossRef]

42. Dimitriou, K.; Kassomenos, P. Local and regional sources of fine and coarse particulate matter based on traffic and background monitoring. Theor. Appl. Clim. 2013, 116, 413-433. [CrossRef]

43. Masoudi, M.; Tan, P. Multi-year comparison of the effects of spatial pattern of urban green spaces on urban land sur-face temperature. Landscape Urban Plann. 2019, 184, 44-58. [CrossRef]

44. Song, Y.; Song, X.; Shao, G. Effects of Green Space Patterns on Urban Thermal Environment at Multiple Spatial-Temporal Scales. Sustainable 2020, 12, 6850. [CrossRef]

45. Beijing Meteorological Bureau. Climatic Characteristics of Beijing 2019. 2019. Available online: http://bj.cma.gov.cn/xwzx/ qxyw/202001/t20200115_1380086.html (accessed on 13 January 2020).

46. Sun, C.-Y. A street thermal environment study in summer by the mobile transect technique. Theor. Appl. Clim. 2011, 106, 433-442. [CrossRef]

47. Matzarakis, A.; Rutz, F.; Mayer, H. Modelling radiation fluxes in simple and complex environments-application of the RayMan model. Int. J. Biometeorol. 2007, 51, 323-334. [CrossRef] [PubMed]

48. Mori, J.; Sæbø, A.; Hanslin, H.M.; Teani, A.; Ferrini, F.; Fini, A.; Burchi, G. Deposition of traffic-related air pollutants on leaves of six evergreen shrub species during a Mediterranean summer season. Urban For. Urban Green. 2015, 14, 264-273. [CrossRef]

49. Xu, Y.; Xu, W.; Mo, L.; Heal, M.R.; Xu, X.; Yu, X. Quantifying particulate matter accumulated on leaves by 17 species of urban trees in Beijing, China. Environ. Sci. Pollut. Res. 2018, 25, 12545-12556. [CrossRef] [PubMed] 
50. Qin, Z.; Li, Z.; Cheng, F.; Chen, J.; Liang, B. Influence of canopy structural characteristics on cooling and humidifying effects of Populus tomentosa community on calm sunny summer days. Landsc. Urban Plan. 2014, 127, 75-82. [CrossRef]

51. Liu, J.; Li, S.; Wu, F.; Liu, J.; Zhang, Z. The ecological effects between pure woodland and mixed of urban green space. Acta Ecol. Sin. 2007, 27, 674-684.

52. Qin, J.; Wang, L.; Hu, Y.; Zhang, M.; You, W. Effect of Plant Community on Temperature Lowering and Humidity Increasing in Residential Areas of Shanghai. J. Ecol. R. Environ. 2009, 25, 92-95.

53. Zhu, C.; Ji, P.; Li, S. Effects of the different structure of urban green belts on the air quality. J. Nanjing Forestry Univ. (Nat. Sci. Ed.) 2013, 37, 18-24.

54. Gao, G.; Sun, F.; Thao, N.T.T.; Lun, X.; Yu, X. Different Concentrations of TSP, PM10, PM2.5, and PM1 of Several Urban Forest Types in Different Seasons. Pol. J. Environ. Stud. 2015, 24, 2387-2395. [CrossRef]

55. Nguyen, T.; Yu, X.; Zhang, Z.; Liu, M.; Liu, X. Relationship between types of urban forest and PM2.5 capture at three growth stages of leaves. J. Environ. Sci. 2015, 27, 33-41. [CrossRef] [PubMed]

56. Tallis, M.; Taylor, G.; Sinnett, D.; Freer-Smith, P. Estimating the removal of atmospheric particulate pollution by the urban tree canopy of London, under current and future environments. Landsc. Urban Plan. 2011, 103, 129-138. [CrossRef]

57. Fan, S.X.; Yan, H.; Qi, S.M.Y.; Bai, W.L.; Pi, D.J.; Li, X.; Dong, L. Dust capturing capacities of twenty-six deciduous broad-leaved trees in Beijing. Chin. J. Plant Ecol. 2015, 39, 736-745. [CrossRef]

58. Popek, R.; Gawrońska, H.; Wrochna, M.; Gawroński, S.W.; Saebø, A. Particulate Matter on Foliage of 13 Woody Species: Deposition on Surfaces and Phytostabilisation in Waxes-A 3-Year Study. Int. J. Phytoremed. 2013, 15, 245-256. [CrossRef] [PubMed]

59. Hallquist, M.; Wenger, J.C.; Baltensperger, U.; Rudich, Y.; Simpson, D.; Claeys, M.; Dommen, J.; Donahue, N.M.; George, C.; Goldstein, A.H.; et al. The formation, properties and impact of secondary organic aerosol: Current and emerging issues. Atmos. Chem. Phys. 2009, 9, 5155-5236. [CrossRef]

60. Schaubroeck, T.; Deckmyn, G.; Neirynck, J.; Staelens, J.; Adriaenssens, S.; Dewulf, J.; Muys, B.; Verheyen, K. Multilayered Modeling of Particulate Matter Removal by a Growing Forest over Time, From Plant Surface Deposition to Washoff via Rainfall. Environ. Sci. Technol. 2014, 48, 10785-10794. [CrossRef] 